\title{
Substituição natural de rainhas fisogástricas e distância de vôo dos machos em Tiuba (Melipona compressipes fasciculata Smith, 1854) e Uruçu (Melipona scutellaris Latreille, 1811) (Apidae, Meliponini).
}

\author{
Gislene Almeida CARVALHO-ZILSE ${ }^{1}$; Warwick Estevam KERR ${ }^{2}$
}

\section{RESUMO}

Este trabalho relata detalhes da vida reprodutiva de duas espécies de abelhas sem ferrão. Rainhas velhas de Melipona compressipes fasciculata, no Maranhão, morrem e são substituídas com sucesso em todos os meses. Rainhas de Melipona scutellaris, trazidas de Lençóis (BA - nordeste do Brasil) para Uberlândia (MG, centro-sudeste do Brasil) morreram durante todos os meses e não mostraram a existência de trimestre preferencial para as novas rainhas iniciarem postura. Quarenta machos de $M$. scutellaris, após serem marcados no tórax e libertados em grupos de 10 a 100, 400, 800 e 1000 metros do meliponário, tiveram seus retornos observados. Todos os machos libertados a 100 e 400 metros regressaram ao meliponário, 7 de 10 machos e 2 de 10 machos retornaram de 800 e 1000 metros, respectivamente. Os machos esperam constantemente pela saída de uma rainha virgem, próximos às colônias órfãs, o que indica que a maioria das rainhas é inseminada próximo aos seus ninhos, portanto, a dispersão dos genes depende do vôo dos machos e da distância de enxameagem para ocupação de uma cavidade para o novo ninho.

\section{PALAVRAS-CHAVE}

meliponineos, postura, enxameagem

\section{Natural substitutions of queens and flight distance of males in tiuba (Melipona compressipes fasciculata Smith, 1854) and uruçu (Melipona scutellaris Latreille, 1811) (Apidae, Meliponini).}

\begin{abstract}
This work reports on the reproductive life of the stingless bees (Meliponini). Old queens of Melipona compressipes fasciculata in Maranhão State, Brazil die and are successfully substituted by new ones in all months. Queens of Melipona scutellaris from Lençois (BA - northeastern Brazil) brought to Uberlândia (Central South eastern Brazil) died during all months, and there are no months where new queens are more able to begin egg laying. Forty males of M. scutellaris were marked in the thorax and released in groups of 10 at 100, 400, 800 and 1000 meters from the meliponary and their return to it was observed. All males released at 100 to 400 meters returned, 7 out of 10 and 2 out of 10 males returned respectively from 800 and 1000 meters. Males are constantly waiting for a virgin queen next to orphan colonies, the majority of the queens is inseminated in near the hive, therefore, gene dispersion depends more upon the males and of the occupation of a new cavity for nest.
\end{abstract}

KEY WORDS

meliponini, egg laying, swarm

${ }^{1}$ Grupo de Pesquisas em Abelhas, CPCA, INPA, Av. André Araújo 2936, Bairro Petrópolis, 69.083-060, Manaus/AM, Fone: (92)642.3440, gislene@inpa.gov.br; ${ }^{2}$ Universidade Federal de Uberlândia, INGEB, Campus Umuarama Bloco 2E Sala 20, 38400-902, Uberlândia/MG, Fone: (34)3211.6293, kerr@ufu.br. 


\section{ACTA \\ AMAZONICA}

SUBSTITUIÇÃO NATURAL DE RAINHAS FISOGÁSTRICAS E DISTÂNCIA DE VÔO DOS MACHOS

EM TIUBA (Melipona compressipes fasciculata SMITH, 1854) E URUÇU (Melipona scutellaris...

\section{INTRODUÇÃO}

A grande necessidade de se conservar as 192 espécies de meliponíneos (Silveira et al., 2002) brasileiros (abelhas sem ferrão) jaz, principalmente, na sua ampla ação polinizadora da nossa flora que, por sua vez, garante a presença e desenvolvimento de nossa fauna e da nossa biodiversidade (Kerr et al., 1996). Pott \& Pott (1994) constataram que, das cerca de 500 espécies de plantas floríferas pantaneiras que descrevem, cerca de 150 (30\%) são polinizadas por nossas abelhas nativas. Há muitas espécies de plantas que são visitadas por uma única espécie de abelhas como foi observado por Absy et al. (1984) na região do médio Amazonas (Rio Tapajós).

As populações de abelhas sociais brasileiras vêm sendo destruídas rapidamente, especialmente devido aos coletores de mel (que após retirarem o mel, jogam a cria fora) e a destruição dos seus habitats (Kerr et al.,1994). Buarque de Holanda (1957) cita que os bandeirantes, após caminharem e trabalharem, iam procurar e "tirar" mel de abelhas. Além disso, o sistema de determinação do sexo nessas abelhas, baseado em 25 a 30 genes $c s d$, leva à necessidade da população ter um número mínimo de 44 colônias, numa mesma área de reprodução, para que produção de machos diplóides não leve a população a extinção (Kerr \& Vencovsky, 1982; Page et al., 1983; Carvalho, 2001).

As poucas informações sobre o processo reprodutivo das espécies de meliponíneos e sua grande diversidade comportamental demonstram a importância de conhecer um pouco mais sobre este aspecto, a fim de orientar operações de manejo e métodos de melhoramentos.

Assim, este trabalho teve como objetivo conhecer um pouco mais sobre o processo reprodutivo em Melipona compressipes fasciculata Smith, 1854 e Melipona scutellaris Latreille, 1811 quanto a: 1) freqüência natural de substituição de rainhas; 2) tempo de vida da rainha fecundada e 3) distância de vôo dos machos.

As duas espécies estudadas são de grande relevância para a meliponicultura nacional: $M$. compressipes fasciculata é, certamente, a principal abelha domesticada no Brasil e se distribui geograficamente desde o Maranhão até o Pará (Kerr, 1996) e M. scutellaris que é a abelha mais cultivada em todo o Nordeste brasileiro, ocupando os estados da Bahia até o Rio Grande do Norte (Kerr et al., 1996).

\section{MATERIAL E MÉTODOS}

Colméias órfãs, recém formadas a partir de multiplicação artificial de colônias fortes de $M$. compressipes no Meliponário K (São Luis - Maranhão clima quente) e de colônias $M$. scutellaris instaladas no Meliponário Uberlândia (Uberlândia - Minas Gerais, clima com estações fria e quente bem definidas) foram acompanhadas semanalmente até a formação e fecundação de suas novas rainhas.

Imediatamente depois de confirmado o inicio da postura, por observação direta da colônia, as novas rainhas foram marcadas no tórax, com tinta atóxica (à base d'água) a fim de facilitar o monitoramento do processo de substituição natural das mesmas. As substituições naturais ocorridas foram acompanhadas e os registros de morte das rainhas velhas foram catalogados, em fichas individuais de observação, assim como o início da postura das novas rainhas formadas nos anos de 1990 a 1999.

Foram montadas três caixas de observação, para acompanhamento do processo de postura em $M$. scutellaris, no laboratório de Genética da Universidade Federal de Uberlândia. As caixas de observação eram de madeira e

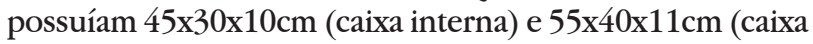
externa) e tampa de vidro.

Kerr et al. (1962) usando purpurina de diferentes cores para marcar machos de Scaptotrigona postica Latreille, 1907 de diferentes colônias, constataram que em cada agrupamento de machos havia indivíduos de todas as colônias. Utilizou-se técnica semelhante para verificar a distância que machos de $M$. scutellaris retornavam para o aglomeramento de machos que ficava no meliponário em Uberlândia, MG. Em março de 1998, 40 indivíduos adultos foram coletados, com auxílio de puçá, em agrupamentos dos mesmos nas proximidades das colônias (prateleiras e/ou paredes do meliponário). Os machos foram marcados no tórax (tinta atóxica) e transportados em recipientes plásticos com ventilação apropriada, a distâncias de 100, 400, 800 e 1000 metros do meliponário. Grupos de 10 indivíduos foram libertados no período da manhã nas respectivas distâncias e, durante 1 hora, foram realizadas observações no local em que foram coletados (agrupamento de machos).

\section{RESULTADOS E DISCUSSÃO}

Durante o monitoramento das rainhas nas caixas de observação, por três vezes foi registrado que durante o processo de substituição da rainha fecundada de M.scutellaris, a nova rainha era escolhida pelas operárias e fazia o vôo nupcial ainda na presença da rainha velha, o que explica observações casuais de duas rainhas fisogástricas numa mesma colônia, por criadores dessas abelhas. Bego (1983) relatou a presença de mais de uma rainha fisogástrica ativa em colônias de Melipona bicolor Lepeletier, 1836, espécie, que segundo a autora, apresentou poliginia facultativa com até 5 rainhas ativas. Cappas e Souza (2000) relatou a existência de poliginia com até 3 rainhas em $M$. quadrifasciata Lepeletier, 1836.

Foi observado que as rainhas de M. compressipes apresentaram uma longevidade máxima de 84 meses ( 7 anos), enquanto que as rainhas de $M$. scutellaris apresentaram uma média de sobrevivência de 22 meses e longevidade máxima também de 7 anos.

Os registros de mortes naturais das rainhas (Tabelas I e II) não apresentaram nenhuma diferença estatística entre os quatro trimestres do ano. O fato de São Luis possuir clima quente durante todo ano e do Meliponário K estar 


\section{ACTA AMAZONICA}

localizado próximo a uma região de mangue com fornecimento de pólen e néctar para as colônias, permitiu o bom desenvolvimento das colônias e a ocorrência do processo de substituição natural das rainhas. Apesar de Uberlândia possuir estação fria (maio a julho) e quente (agosto a abril) bem definidas, as colônias estavam alojadas numa área próxima à mata nativa (cerrado) e dentro de um pomar com vasto pasto apícola disponível. Isso indica que em condições adequadas de clima e pasto apícola, as colônias de $M$. compressipes não apresentaram trimestre preferencial para substituição natural de suas rainhas ativas nem a estação fria de Uberlândia influenciou a taxa de substituição de rainhas de M. scutellaris. Vale salientar que o tempo médio esperado de formação da nova rainha (processo de escolha da nova rainha, realização do vôo

Tabela 1 - Freqüência mensal de mortes de rainhas fisogástricas de Melipona compressipes fasciculata, em São Luis (MA), período de 1990 a 1999.

\begin{tabular}{lcc}
\hline \hline Mês da morte & $\begin{array}{c}\text { Número de } \\
\text { rainhas mortas }\end{array}$ & X2(n' esp. $=55 / 4=13,75)$ \\
\hline Março & 5 & 0,76 \\
Abril & 7 & \\
Maio & 5 & 2,40 \\
\hline Junho & 1 & \\
Julho & 1 & \\
Agosto & 6 & 0,11 \\
\hline Setembro & 4 & \\
Outubro & 6 & 0,11 \\
Novembro & 5 & \\
\hline Janeiro & 5 & \\
Fevereiro & 4 & \\
Dezembro & 6 & \\
\hline TOTAL & 55 & \\
\hline \hline
\end{tabular}

Tabela 2 - Freqüência mensal de mortes de rainhas fisogástricas de Melipona scutellaris em Uberlândia, MG, período de 1990 a 1999.

\begin{tabular}{lcc}
\hline \hline Mês da morte & $\begin{array}{c}\text { Número de } \\
\text { rainhas mortas }\end{array}$ & X2(n' esp. $=28 / 4=7)$ \\
\hline Março & 03 & 0,14 \\
Abril & 03 & \\
Maio & 02 & 0,00 \\
\hline Junho & 01 & \\
Julho & 03 & \\
Agosto & 03 & 3,57 \\
\hline Setembro & 00 & \\
Outubro & 02 & 2,28 \\
Novembro & 00 & \\
\hline Dezembro & 07 & \\
Fevereiro & 03 & \\
Janeiro & 01 & \\
\hline TOTAL & 28 & \\
\hline \hline
\end{tabular}

nupcial e início de postura) é curto sendo de 14 a 15 dias para M. compressipes (Kerr, 1996) e de 6 dias para $M$. scutellaris (Kerr etal., 1996).

Quanto ao início de postura das novas rainhas de $M$. scutellaris em Uberlândia, também não foi verificado nenhum trimestre preferencial para ocorrência deste processo ao longo dos meses do ano (Tabela III). Esses resultados podem ser justificados pelas mesmas considerações de pastagem disponível e clima favorável. Mesmo no período frio (em Uberlândia) as colônias conseguiram manter suas temperaturas internas visto que estavam alojadas em colméias racionais "Modelo Uberlândia" (Kerr et al., 1996) com parede tríplice constituída de madeira $(1,5 \mathrm{~cm}$ de espessura) + isopor $(0,5 \mathrm{~cm})+$ lâmina de eucatex $(0,5 \mathrm{~cm})$, especialmente proposta para esse fim.

Foi verificado que todos os machos de $M$. scutellaris libertados regressaram ao meliponário nas distâncias de 100 até 400 metros. Dos 10 machos libertados a 800 metros, 7 regressaram e 3 não foram vistos até o dia seguinte. Dos 10 machos libertados a 1000 metros apenas 2 regressaram ao meliponário. Kerr et al. (1962) notaram que zangões de Scaptotrigona postica Latreille, 1807 têm um raio de vôo de pouco mais de 600 metros, sendo o único relato para machos de meliponíneos. Para operárias, há registro de até 3000 metros de raio de vôo em Melipona subnitida Ducke, 1910 (Bruening, 1990 apud Nogueira-Neto, 1997). Os resultados do presente trabalho indicam que a maioria dos machos (70\%) de M. scutellaris voa até cerca de 800 metros. Apenas poucos machos (20\%) voaram a mais de 1.000 metros de distância das suas colônias de origem. Essa distância representa a área de forrageamento dos mesmos, já que as colônias do meliponário representavam uma população finita devido ao fato de $M$. scutellaris não ser nativa de Uberlândia e não haver nenhum outro criadouro com essa espécie na região. Sabe-se que os machos saem

Tabela 3 - Freqüência mensal de início de postura de rainhas de Melipona scutellaris em Uberlândia, MG, período de 1990 a 1999.

\begin{tabular}{lcc}
\hline $\begin{array}{l}\text { Mês de início } \\
\text { de postura }\end{array}$ & $\begin{array}{c}\text { Número de } \\
\text { rainhas }\end{array}$ & X2(n' esp. $=56 / 4=14)$ \\
\hline Março & 5 & 0,60 \\
Abril & 5 & \\
Maio & 7 & 1,78 \\
\hline Junho & 3 & \\
Julho & 1 & \\
Agosto & 5 & 0,07 \\
\hline Setembro & 6 & \\
Outubro & 4 & 0,07 \\
Novembro & 5 & \\
\hline Dezembro & 7 & \\
Janeiro & 4 & \\
Fevereiro & 4 & \\
\hline TOTAL & 56 & \\
\hline \hline
\end{tabular}




\section{ACTA AMAZONICA}

SUBSTITUIÇÃO NATURAL DE RAINHAS FISOGÁSTRICAS E DISTÂNCIA DE VÔO DOS MACHOS

EM TIUBA (Melipona compressipes fasciculata SMITH, 1854) E URUÇU (Melipona scutellaris... ou são expulsos e não retornam às colônias ao atingirem a maturidade sexual: de 11 a 14 dias de idade em $M$. compressipes (Kerr, 1996) e de 9 a 11 dias em M. scutellaris (Abreu e Penna, 1992). Assim, têm que se alimentar diretamente nas flores após saírem das colônias. Os machos formam agrupamentos próximos à colônias órfãs na tentativa de copular com alguma rainha virgem (Kerr et al., 1996). O fato de haver aglomeração de machos próximos às colônias órfãs faz com que as rainhas sejam fecundadas, na maioria das vezes, logo após saírem da colônia. Kerr (1987) relatou que a enxameagem em meliponíneos ocorre a curtas distâncias da colônia matriz, pelo fato das abelhas necessitarem transportar cera e alimento para o novo local de nidificação. Somente após essa arrumação é que a rainha virgem sai para o vôo nupcial. Assim, a dispersão das colônias dessas abelhas fica por conta do raio de vôo dos machos, em busca de rainhas virgens, e do raio de ocupação de um novo ninho por ocasião dos enxameamentos. No caso da Melipona scutellaris esse raio é levemente superior a 1.200 metros: 1.000 metros dos machos e 200 metros, que segundo Kerr (informação pessoal) corresponde à distância máxima estimada de enxameação de uma nova colônia de M. scutellaris.

\section{BIBLIOGRAFIA CITADA}

Abreu, S. A. B.; Penna, M. N. P. 1992. Biologia reprodutiva de meliponíneos. Naturalia, Ed. Especial Encontro Brasileiro sobre Biologia de Abelhas e Outros Insetos Sociais. p. 255.

Absy, M. L.; Camargo, J. M. F.; Kerr, W.E.; Miranda, I. P. A. 1984. Espécies de plantas visitadas por Meliponinae (Hymenoptera, Apidae) para coleta de pólen na região do médio Amazonas. Revista Brasileira de Biologia 44(2): 227-237.

Bego, L. R. 1983. On some aspects of bionomics in Melipona bicolor bicolor Lepeletier (Hymenoptera, Apidae, Meliponinae). Revista Brasileira de Entomologia 27(3/4): 211-224.

Buarque de Holanda, S. 1957. Caminhos e Fronteiras. Coleção documentos brasileiros, dirigida por Octávio Tarquínio de Sousa. Capitulo 3 - A Cera e o Mel. p. 47-61. Livraria José Olimpio Editora, Rio de Janeiro, Brasil.
Cappas e Souza, J. P. 2000. A poligenia em Meliponine. Anais do IV Encontro sobre Abelhas: 279.

Carvalho, G. A. 2001. The number of sex alleles (CSD) in a bee population and its practical importance (Hymenoptera: Apidae). Journal of Hymenoptera Research 10(1):10-15.

Kerr, W. E. 1996. Biologia e manejo da tiúba: a abelba do Maranbão. EDUFMA. São Luis, MA. 156pp.

Kerr, W. E.; Carvalho, G. A.; Nascimento, V. A. 1996. Abelha uruçu: biologia, manejo e conservação. Ed. Fundação Acangaú, Paracatu, MG, 144 pp.

Kerr, W. E.; Nascimento, V. A.; Carvalho, G. A. 1994. Há salvação para os meliponínios? Anais do I Encontro de Abelhas de Ribeirão Preto: 60-65.

Kerr, W. E.; Vencovsky, R.1982. Melhoramento genético de abelhas I. Efeito do número de colônias sobre o melhoramento. Brazilian Journal of Genetics 5: 279-285.

Kerr, W. E.; Zucchi, R.; Nakadaira, J. T.; Butolo, J. E. 1962. Reproduction in the social bees (Hymenoptera, Apidae). Journal of New York Entomological Society 70: 265-276.

Kerr, W. E. 1987. Abelhas indígenas brasileiras (Meliponíneos) na polinização, na produção de mel, pólen geoprópolis e cera. Informe Agropecuário 13(149):15-22.

Nogueira-Neto, P. 1997. Criação Racional de Abelhas Indígenas sem ferrão. São Paulo, Nogueirapis. 445 pp.

Page Jr., R. E.; Laidlaw, H. H.; Erickson, E. H. 1983. Closed population honey bee breeding. 3. Distribution of sex alleles with gyne supersedure. Journal of Apicultural Research 22:184-190.

Pott, A; Pott, V. 1994. Plantas do Pantanal. EMBRAPA/CPAP, Corumbá, MT. 320pp.

Silveira, F. A.; Melo, G. A.; Almeida, E. A. B. 2002. Abelhas brasileiras: sistemática e identificação. $1^{\mathrm{a}}$ Ed. MMA e Fund. Araucária, Belo Horizonte - MG. 253pp.

RECEBIDO EM: 16/02/2001 ACEITO EM: 27/07/2004 